\title{
Conceptual Frameworks for Assessing Climate Change Effects on Urban Areas: A Scoping Review
}

\author{
Florian Klopfer*(D), René Westerholt (D) and Dietwald Gruehn (iD \\ Department of Spatial Planning, TU Dortmund University, August-Schmidt-Straße 10, 44227 Dortmund, \\ Germany; rene.westerholt@tu-dortmund.de (R.W.); dietwald.gruehn@tu-dortmund.de (D.G.) \\ * Correspondence: florian.klopfer@tu-dortmund.de
}

Citation: Klopfer, F.; Westerholt, R.; Gruehn, D. Conceptual Frameworks for Assessing Climate Change Effects on Urban Areas: A Scoping Review. Sustainability 2021, 13, 10794. https: / / doi.org/10.3390/ su131910794

Academic Editor: Adriana Del Borghi

Received: 30 August 2021

Accepted: 23 September 2021

Published: 28 September 2021

Publisher's Note: MDPI stays neutral with regard to jurisdictional claims in published maps and institutional affiliations.

Copyright: (C) 2021 by the authors. Licensee MDPI, Basel, Switzerland. This article is an open access article distributed under the terms and conditions of the Creative Commons Attribution (CC BY) license (https:/ / creativecommons.org/licenses/by/ $4.0 /)$.

\begin{abstract}
Urban areas are amongst the most adversely affected regions by current and future climate change effects. One issue when it comes to measuring, for example, impacts, vulnerabilities, and resilience in preparation of adaptation action is the abundance of conceptual frameworks and associated definitions. Frequently, those definitions contradict each other and shift over time. Prominently, in the transition from the IPCC AR (International Panel on Climate Change Assessment Report) 4 to the IPCC AR 5, a number of conceptual understandings have changed. By integrating common concepts, the literature review presented intends to thoroughly investigate frameworks applied to assess climate change effects on urban areas, creating an evidence base for research and politically relevant adaptation. Thereby, questions concerning the temporal development of publication activity, the geographical scopes of studies and authors, and the dominant concepts as applied in the studies are addressed. A total of 50 publications is identified following screening titles, abstracts, and full texts successively based on inclusion and exclusion criteria. Major findings derived from our literature corpus include a recently rising trend in the number of publications, a focus on Chinese cities, an imbalance in favor of authors from Europe and North America, a dominance of the concept of vulnerability, and a strong influence of the IPCC publications. However, confusion regarding various understandings remains. Future research should focus on mainstreaming and unifying conceptual frameworks and definitions as well as on conducting comparative studies.
\end{abstract}

Keywords: climate change adaptation; systematic literature review; urban climate; vulnerability assessment

\section{Introduction}

Climate change is one of the most pertinent global issues to threaten urban areas. In 2019 , about 4.3 billion people, and thus more than $56 \%$ of the global population, were living in urban environments. For high-income countries, this share is as high as $81 \%$, while for low-income countries, it is still at about 33\%. Population growth rates of already urbanized high-income countries are low and at only $0.7 \%$ on average, but low-income countries are still growing considerably by $4 \%$ per annum [1]. For 2050, estimates show a global urbanization rate of $68.4 \%$ [2]. This increase in urban population will promote climate change, and cities with their concentration of inhabitants in addition contribute to a higher degree to the global greenhouse gas (GHG) emissions through their concentration of economic activities compared to rural areas. With about $75 \%$ of the global populationincluding some of the largest cities-being located in low and middle-income countries, climate change will thus become a considerable threat, especially for vulnerable urban communities in the Global South. The Intergovernmental Panel on Climate Change (IPCC) Assessment Report (AR) 5, therefore, has concluded a concentration of key and emerging climate risks, especially in urban areas. Conurbations hence need to accelerate their efforts towards climate change adaptation in order to increase their resilience [3,4]. There is no universal understanding of what makes a settlement an urban area. Especially finding 
a suitable categorization for smaller communities is often difficult [3]. The aim of what follows in this article is to review literature from several national backgrounds. We, therefore, follow the UN understanding of urban, meaning that we apply the respective definitions that are used in the countries considered [2]. This kind of approach is often applied in studies with an international outlook. The angle of the present review is hence a broad one covering a range of different types of urban areas.

Numerous definitions, concepts, and ideas have been proposed and applied in the context of assessing climate change effects on urban areas. These concepts and ideas define both universes of discourse and analytical frameworks. However, for terms such as vulnerability, impact, hazard, risk, or resilience, an abundance of definitions and understandings exist, some of which contradict each other ([5-7] — specifically regarding vulnerability; [8] -for adaptation; [9] —for adaptive capacity). Furthermore, concepts and their understandings change over time. Notably, from the IPCC AR 4 to the AR 5, a significant transition took place regarding a variety of definitions and concepts (see also Figure 1). The IPCC went from a vulnerability (AR 4) to a risk-based (AR 5) conception of climate change adaptation. Hereby, it also harmonized the climate change adaptation community with neighboring disciplines, such as disaster risk management [10]. On the one hand, the IPCC AR 4 [11], as well as the IPCC TAR [12] feature a vulnerability approach. Vulnerability thereby represents the outcome of an assessment of the exposure to climate change, the sensitivity of a system, subsequent impacts, and the adaptive capacity of the system to these impacts (see also [13]). Vulnerability can thus be understood as a function of exposition towards a climate signal, sensitivity towards the signal, and the adaptive capacity of the system. On the other hand, the 2012 Special Report on Managing the Risks of Extreme Events and Disasters to Advance Climate Change Adaptation (SREX) [14] and the AR 5 [15] changed to a risk-based approach. There is now a clear distinction between vulnerability and risk [6]. Vulnerability is understood as a component of the risk of an exposed system [15]. The vulnerability of a system or a society is different from the impact on a system (e.g., temperature rise). For an adequate adaptation, parallel consideration of changes in climate and changes in society is necessary [6]. Risk can be seen as a function of hazard, exposure, and vulnerability. However, the dynamic conceptual diversity outlined above highlights the need for an overview of conceptual understandings for future comparative studies.

Ongoing shifts in conceptual understandings require a comprehensive overview of how climate change effects have been assessed. Preconditions for adaptation and prerequisites for adaption action are built regarding vulnerability and risk as well as studying or assessing adaptive capacity and many more (see, e.g., [16] for vulnerability assessments as a determinant of what and how to adapt; [9] for adaptive capacity). Tonmoy et al. [17] found that regarding climate change vulnerability assessments, the literature originates from a variety of research areas, such as risk assessment, natural disaster management, and urban planning. That makes it challenging to obtain the main directions and key methods in this area. Berrang-Ford et al. [18] also stated that recent controversy has brought up calls for more standardization and transparency in the methodologies applied to unify climate change research. They furthermore ask for a vigorous conceptual and methodological development of systematic review approaches tackling methodological challenges, such as unifying and monitoring climate change adaptation.

The systematic literature review that follows offers a comprehensive overview of frameworks that are used to assess the effects that climate change has on urban areas. The term 'framework' as it is used in the remainder of this article thereby describes top-level systems of sub-concepts including vulnerability, risk, or sensitivity that are used in climate change research. In addition, we have chosen to focus on 'urban' because we argue that climate change-related research faces different problems in urban areas than in rural areas and that these challenges also play out in different ways at the conceptual level. We thereby follow the arguments of researchers who propose an explicitly urban adaptation of concepts, such as vulnerability and resilience and suggest a systemic and conceptual 
difference between urban and other areas when it comes to climate change impacts $[19,20]$. Our goal is to provide a holistic picture instead of focusing only on a few selected concepts or applied fields. We thus investigate the status quo of top-level frameworks applied and reveal trends, inconsistencies, and potential conceptual conflicts. Thereby, we hope to present useful information for both researchers and practitioners in the field alike. It is of note that we do not intend to propose or promote a 'good' framework in an evaluative sense or guidelines for what shall be done and what frameworks and methods practitioners should apply. We rather intend to raise awareness for possible issues and thus to aid future climate change-related research and practice.
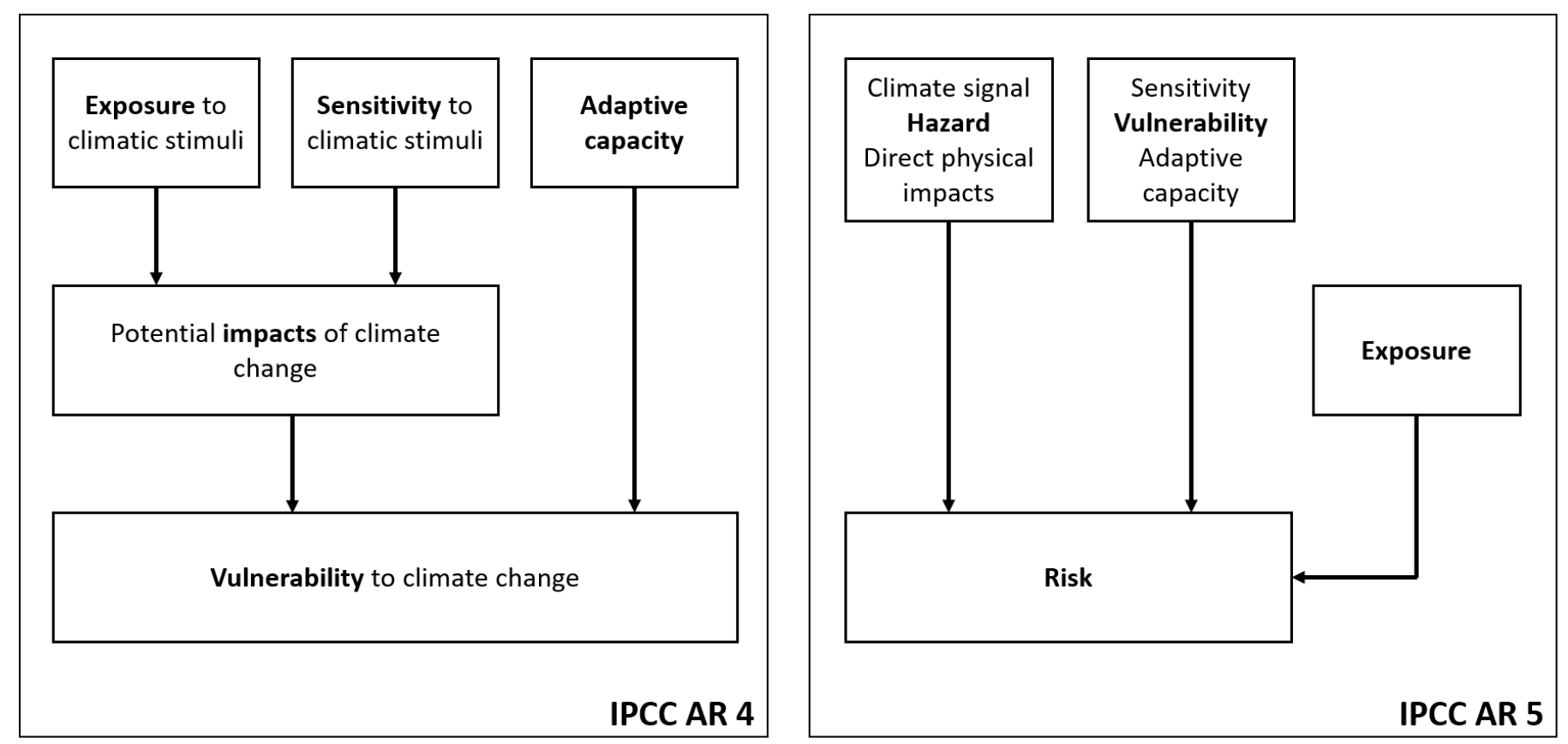

Figure 1. Comparison of the AR 4 and AR 5 IPCC risk and vulnerability concept (based on $[11,13,15,21])$.

Only a limited number of systematic and non-systematic reviews have been undertaken on conceptual frameworks applied to assess climate change effects in urban areas. Our literature review is guided by the following overarching research question:

What conceptual frameworks for assessing climate change effects in urban areas are applied in the scholarly literature?

The literature to be researched in order to address this broad question is narrowed down by applying a number of exclusion and inclusion criteria (see Section 3), such as limiting publication dates to 2014 until today. In addition, several subordinate questions are intended to make answering the broad guiding question more manageable by highlighting specific aspects in each case. These sub-questions are:

RQ 1: Are there trends regarding the publication activity concerning relevant studies in the considered time period, and how can disclosed characteristics be explained?

RQ 2: What are the geographical scopes of respective studies, and where are the authors located?

RQ 3: What study types dominate-case studies or conceptual/theoretical works, quantitative or qualitative analyses, and what target audiences are focused on by the reviewed studies?

RQ 4: What climate change-related conceptual frameworks do authors refer to, and how are they defined?

The remainder of the article is structured as follows. Section 2 presents the state-of-theart regarding literature reviews touching upon the topic of the review. Section 3 introduces 
the methodology applied before Section 4 features the results generated from the review and discusses them, while Sections 5 and 6 conclude the paper.

\section{Reviews in Climate Change Adaptation Related Research}

Being applied predominantly in health-related sciences, Berrang-Ford et al. [18], in their review of reviews, showed that the numbers of systematic reviews are on the rise as well in climate change adaptation research. Siders [9] stated that as systematic literature reviews offer objective criteria and transparency, they are useful, especially in climate adaptation, to synthesize results and identify gaps. Possible methods mentioned hereby are qualitative content analysis, bibliometric analysis, and citation network analysis.

Climate change-related literature reviews exist on diverse topics, such as climate change vulnerability assessment in India [22], climate change adaptation, and water resource management [23], or the threatening of cultural heritage resources by climate change [24]. Hafezi et al. [25] did a review on climate change adaptation and the impact on policies (methods/tools applied) in coastal areas and on small islands, respectively. Within their research concerning a systems' network approach for climate change vulnerability assessment, Debortoli et al. [26] also conducted a systematic literature review. Hereby they searched for climate change vulnerability case studies set in the Canadian Arctic in order to select index variables and understand their relationships. Bibliometric analyses of climate change vulnerability assessments were done by DiMatteo et al. [16] and Zhang et al. [27]. Biesbroek et al. [8] intended to systematically capture and assess "the current state of larger-n ( $n \geq 20$ cases) comparative adaptation policy literature"(p. 1). Berrang-Ford et al. [18], as touched on above, conducted a review of reviews related to climate change adaptation research. They furthermore introduced guidelines on how to do a systematic review in that field.

When it comes to urban areas and cities, only review studies dealing with particular, relatively narrow issues, such as the impact of urbanization and climate change on urban temperatures [28], urban flooding, and urban water quality [29], or the planning and design of urban drainage systems [30], are found. Hunt and Watkiss, in 2011, also found a majority of single-issue studies in their review, with sea-level rise being the most common [31]. Dhar Khirfan et al. [32] investigated "the extent and the nature of how the urban planning literature has addressed climate change adaptation"(p. 602). They, therefore, reviewed a predefined set of relevant journals.

The aforementioned review by Hunt and Watkiss [31] is titled Climate change impacts and adaptation in cities: a review of the literature. However, their primary goal was to identify "the state-of-the-art in the quantification and valuation of climate risks at the city-scale" (p. 13). Hereby, they focused on determining what specific sectors of an urban area are most at risk. Furthermore, their selection and analyses of studies were neither systematic nor exhaustive and focused on major world cities [31]. Thus, to our knowledge, as far as urban areas and cities are concerned, there is no (systematic) literature review assessing how a comprehensive evidence base for adaptation is created apart from the review incorporated in IPCC AR 5 [3].

\section{Methodology}

Systematic literature reviews are used to evaluate and interpret corpora of existing literature, for instance, regarding some specific research question or to summarize a field of research [33]. This is done by applying a methodology that ensures transparency and reproducibility [18]. Thus, systematic literature reviews have some important advantages over traditional narrative/meta-analytical assessments. Systematic reviews allow for the thorough determination of general aspects of studies, such as number, type, or geographical aspects. Especially for interdisciplinary research with related literature featuring both quantitative and qualitative methods, this approach is well-suited [34]; for an extensive compilation of motivations, see also [35]. Regarding systematic reviews, there is no one size fits all. Even though established guidelines exist, these, at the same time, need to 
be flexible and adjustable regarding specific cases [18]. We leaned our approach on the well-established PRISMA framework [36] and also embraced the components proposed by Berrang-Ford et al. [18] for reviews in the field of climate change adaptation. We furthermore considered the key components requested by the ROSES reporting guidance that was explicitly developed for environmental systematic reviews and maps [37].

\subsection{Keywords and Databases}

The goal of the present review is to establish a broad understanding of the conceptual frameworks that have been applied to assess climate change effects in urban areas. Therefore, we needed to take a broad perspective. The following Table 1 below gives the keywords that were applied in our review. The keywords presented were the result of a first screening of the literature that was relevant to the topic with respect to the terms included in the IPCC frameworks (see Figure 1), as well as an iterative expansion of the initial set of keywords.

Table 1. Lookup table for the search string creation.

\begin{tabular}{|c|c|c|c|c|c|}
\hline $\begin{array}{l}\text { Sub- } \\
\text { Topics }\end{array}$ & $\begin{array}{l}\text { Climate } \\
\text { AND }\end{array}$ & $\begin{array}{l}\text { Change } \\
\text { AND }\end{array}$ & $\begin{array}{c}\text { Climate Change Effect } \\
\text { Related Component } \\
\text { AND }\end{array}$ & $\begin{array}{c}\text { Assessment Component } \\
\text { AND }\end{array}$ & $\begin{array}{l}\text { Urban } \\
\text { Component }\end{array}$ \\
\hline keywords & climat* & chang * & $\begin{array}{l}\text { vulnerab * OR risk* } \\
\text { OR hazard * OR disaster * } \\
\text { OR resilien * OR adapt* } \\
\text { OR mitigate * OR expos * } \\
\text { OR sensitive * OR impact * } \\
\text { OR suscept * OR influenc * } \\
\text { OR evidenc * OR effect* } \\
\text { OR indicator * OR conceptual } \\
\text { framework* }\end{array}$ & $\begin{array}{l}\text { assess * OR evaluat* } \\
\text { OR rat * OR estimate * } \\
\text { OR measure * OR indicat * } \\
\text { OR descry * OR identif * } \\
\text { OR analy * OR scan * } \\
\text { OR quantif* OR scenario * } \\
\text { OR map * OR method * } \\
\text { OR approach * OR plan * } \\
\text { OR manag } \text { * OR index } \\
\text { OR indices OR concept } \\
\text { OR strateg * }\end{array}$ & $\begin{array}{l}\text { cit * } \\
\text { OR urban * } \\
\text { OR settlement * } \\
\text { OR communit * }\end{array}$ \\
\hline
\end{tabular}

When relevant but yet absent keywords appeared recurrent in titles, keywords, and abstracts of the abovementioned literature corpus resulting from the first screening based on IPCC terms, they were added to the list. The same was done when, for example, at the stage of abstract screening, a new keyword was found to recur and to be a key component of research relevant to the review. Thus, the compilation is insofar dynamic at the initial stages of the review as newly identified keywords were included and additionally retrieved literature was integrated into the process. All previously done research steps were then repeated with the new terms that came up. All keywords are to be understood including the respective inflections (e.g., number or case) indicated here by an asterisk $\left(^{*}\right)$. The table at hand is arranged in such a way that for each sub-topic category of the review, there is a list of synonyms or related terms. For the actual search, at least one keyword from each subtopic was required (AND), while we allowed for flexibility within the sub-topics (OR). The arrangement of the keywords (Table 1) is a breakdown of the overarching research question, as it comprises components covering climate change, climate change effects, assessment, and urban context. Examples of a query string would thus be climate change vulnerability evaluation urban or climate change resilience analysis cities (without considering database characteristics and specifications). A total of 1344 search operations was conducted.).

For the following literature corpus collation, the well-established and often employed databases Scopus and Web of Science (WoS) were considered as they constitute the major general-purpose scientific databases (together with Google Scholar) [38] (except for specialized topics for which specialist databases may be preferred). Scopus and Web of Science offer a variety of detailed search options (for instance, Boolean operators and wildcards), cover a wide range of publication types (including journal articles, several book chapters, and major conference proceedings), cover most relevant disciplines, often feature abstracts, 
and provide functions for the fast and direct integration of bibliographic information into literature management software. Google Scholar was not considered because it does not offer comparable advanced search options and does not allow for sufficiently complex search strings [39]. We applied all components of the query strings to the title of candidate publications. For the urban component (e.g., cit*, urb ${ }^{*}$ ), the abstract and keywords were also scanned as titles tend to be less specific about the respective research settings. Additionally, many studies also name a specific city in their title rather than mentioning terms such as city, cities, or urban areas (see, e.g., [40]). Pre-testing considering all search terms in title, abstract, and keywords led to more than 100,000 retrieved documents (Scopus) meeting the search criteria. This abundance of texts cannot be processed thoroughly in an appropriate time and with reasonable effort. Further steps were therefore undertaken to narrow down the literature corpus further.

\subsection{Language and Temporal Scope}

We restricted the reviewed literature to English language works published from 2014 onwards. The context of our review is an international one, and we expected the bulk of relevant manuscripts to be available in English. Further, since the IPCC AR 5 was issued in 2014 with the abovementioned profound changes in understanding regarding a variety of climate change-related concepts, we did not look further into the past than that year. This approach is in analogy to Dhar and Khirfan [32], who also chose the year of an IPCC report's publication (2001, third assessment report) as a timely constraint for their review. As mentioned above, the report introduces an updated understanding of vulnerability respectively of how the concepts of vulnerability, exposure, and hazards make up risk [15]. This new interpretation/approach has had a big impact on studies on climate change vulnerability and related concepts. Some researchers adopted the new understandings for their conceptual framework [41], others still apply the older IPCC approach [42]. However, the IPCC is considered the "main scientific organization that leads on climate change" [10] (p. 2). Its concept thus marks the start of a new phase of climate change research. Furthermore, the IPCC report provides both a review of relevant literature to date related to climate change adaptation in general and in urban environments, especially $[3,15]$. After using these very general criteria, the title, abstract, and full-text screening was carried out in order to select appropriate literatures by applying further inclusion and exclusion criteria.

\subsection{Record Identification and Screening}

The initial search was conducted in April 2020, with updates done in August and December of the same year. After removing duplicates, a total of 2433 documents was found and organized in the reference management software Citavi.

The first screening step consisted of scanning the titles (see Figure 2 for the entire process). Thereby, documents were considered ineligible when they met at least one of the following exclusion criteria: 


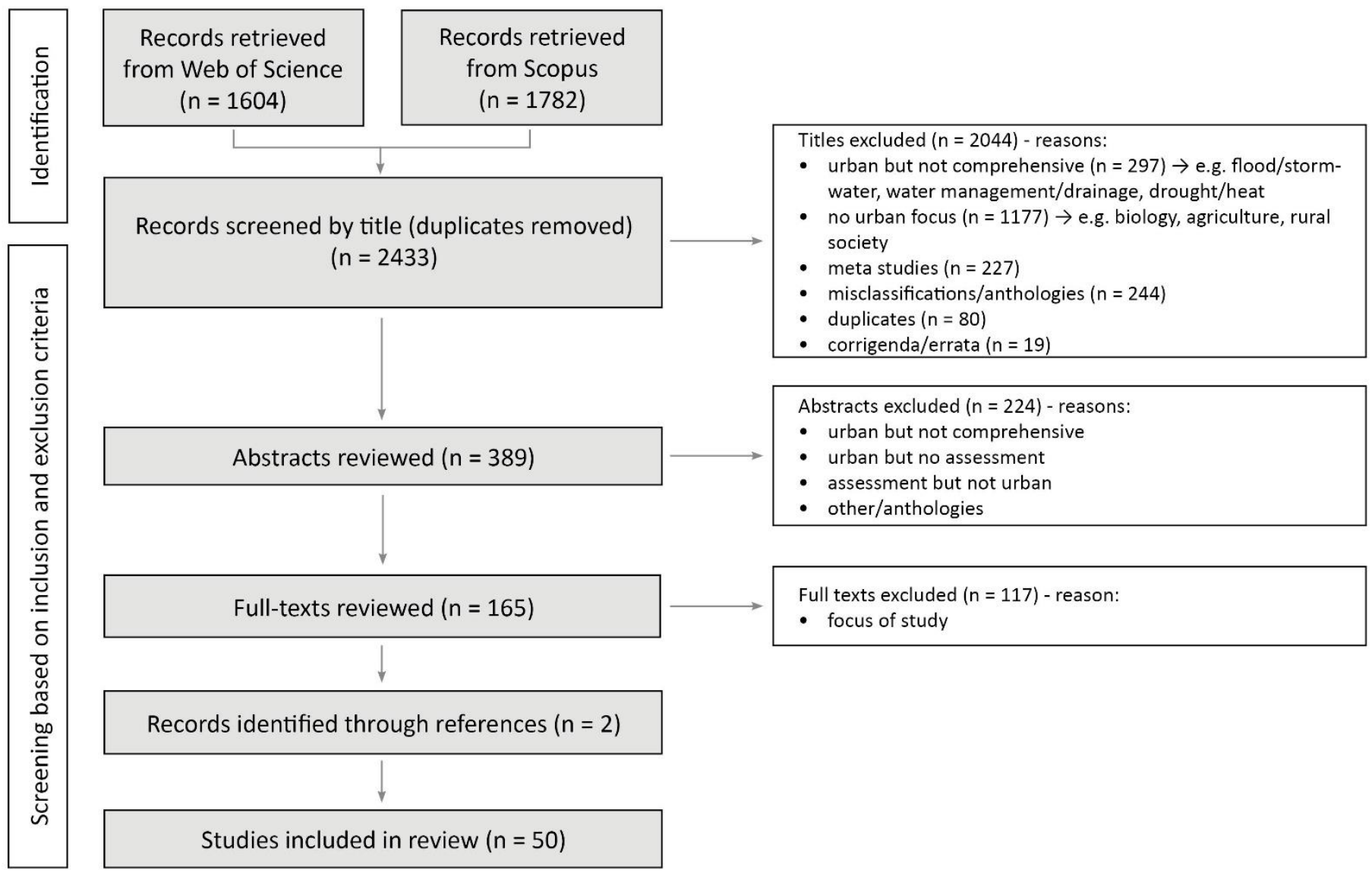

Figure 2. Flow diagram for the different phases of the review process; structure based on Moher et al. [36].

First, there were publications that, although looking at cities/urban areas, did not substantially deal with comprehensive evidence base assessments in urban surroundings $(n=297)$. We are not aiming for a narrow special topic or discipline review approach but rather want to examine frameworks considering urban areas and the climate change effects on them as a whole. Including all studies dealing with the large mass of specific climate change effects, their assessment, and the underlying frameworks led to an unmanageable abundance of literature. Furthermore, it required handling a number of very discipline-specific approaches and technical details. Finally, comprehensive elaborations on conceptual frameworks, such as vulnerability, etc., were not regularly addressed in such studies. Thus, for example, studies dealing with the vulnerability of a specific animal species in an urban context or flooding impacts only were discarded. Flood/stormwater $(n=64)$ or water management/drainage topics $(n=67)$ were the most common specializations here. Examples for the flood/stormwater category are Lyle and Mills [43] and Moore et al. [44]. The water management/drainage fraction contained, e.g., Bai et al. [45] and Feilberg and Mark [46]. Other non-comprehensive city studies were, for example, Garcia Sanchez et al. [47] or Rome et al. [48].

Second, there was a large number $(n=1177)$ of studies dealing with issues located in non-urban areas and often regarding phenomena from a mono-disciplinary perspective, such as biology or political science. The respective category comprised the following subcategories:

- biology, chemistry, ecology: studies focusing on, e.g., flora, fauna, water chemistry, ecosystem services (e.g., [49,50])

- agriculture, forestry, fishery: focus on, e.g., forest management, farmers, yield (e.g., [51,52]) 
- geomorphology, soil topics, fluvial processes, landscape structure: dealing with, e.g., classical physical geography, coastal change, groundwater, water resources, flood, land cover (e.g., [53])

- (rural) society, villages, human issues, health: focusing on the social science component with, e.g., community studies, coping strategies, social groups (e.g., [54,55])

- politics, organizations, infrastructure, economy, etc.: concentrating on, e.g., political science, governance, management approaches, strategies, planning (e.g., [56])

Third, studies considered as meta-studies were discarded $(n=227)$. These publications did not primarily focus on climate change-related issues but rather on side effects, interrelations, or took climate change merely as a setting for other kinds of research (e.g., [57,58].

Fourth, misclassifications, as well as anthologies, were omitted. Sometimes, contributions included in anthologies have separately been published as conference papers, which technically leads to duplicates that we excluded $(n=244)$. Misclassifications sometimes happen with the search algorithm of the database searches (e.g., missing keywords in the title). Furthermore, for example, the fictive title "changing fir growth patterns in boreal climate" meets the criteria that climate and change have to be found in the publication title. However, the study does not deal with climate change but rather changing patterns of fir growth in the boreal climate zone due to unknown reasons

Fifth, 80 duplicates that Citavi did not detect were excluded alongside corrigenda, errata, and extremely short (and thus uninformative) works $(n=19)$. However, works that apparently covered topics such as vulnerability assessment to climate change in general or for a larger region were also considered for the next screening step as they might contain a significant part on urban environments as well. Generally, whenever it was not possible to undoubtedly sort a study out, it was taken to the following screening phase in order not to lose possibly relevant information.

The next step was to screen the abstracts. Thereby, the evaluation of eligibility criteria was more detailed and laborious. Studies located in urban contexts lacking a comprehensive approach (see title check-aiming for holistic studies) (e.g., [59]) were excluded ( $n=47)$. Another 70 publications were sorted in the category urban, no assessment, which comprised works, for example, only describing and evaluating adaptation strategies (see, e.g., [60]) and thus featured no assessment component. A total of 52 elements were identified as not being focused on urban areas, and another 55 were discarded for other reasons (containing some anthologies again). These included analogous to the title screening stage, metastudies such as a review on methodologies for mitigation action evaluation [61], a study on public policy processes in a rural area [62], or a paper evaluating hazard mitigation plans [63]. After checking the abstracts, the full texts of the remaining articles were retrieved $(n=165)$. A total of 48 items were ultimately considered eligible for the review. The other publications $(n=117)$ had an emphasis beyond the scope of the review $[64,65]$ or were not focusing concisely enough on urban areas [66,67]. Literature sections of the eligible full texts were searched for further titles that so far, were not included in the review. Here, two papers were identified. Thus, the final number of publications included for the review was 50. These studies were read and analyzed against the background of the research questions introduced above. Hereby, mainly quantitative analyses in form of descriptive statistics were applied. For answering the questions regarding the main climate changerelated concepts and their respective definitions, the qualitative information extracted from the texts was also presented in a quantified form.

\subsection{Limitations}

Naturally, the methodology applied comes with limitations, and some decisions and approaches are justifiably prone to criticism. Most threats to validity and reliability in systematic reviews arise from bias [35]. To achieve the goal described here, other researchers might have come up with different research questions and other search keywords being searched in alternative databases or languages other than English. Additionally, other time constraints and rationales for applying them are imaginable. The abovementioned 
search of all keywords in abstracts that leads to an unmanageable amount of literature to review would also possibly yield more research relevant to the topic. This is also true for varying definitions of urban or urban areas. However, as mentioned above, the process of a systematic literature review allows for a high degree of transparency, reproducibility, and thus comprehension. This is also basically valid for the decisions on whether to include or exclude publications at the respective review stages. That being said, the review at hand offers a systematic overview following previously described traceable steps.

\section{Results and Discussion}

The following section highlights, discusses, and interprets the findings from the analysis of the eligible set of publications guided by the research questions asked.

RQ 1: Are there trends regarding the publication activity concerning relevant studies in the considered time period, and how can disclosed characteristics be explained?

The timely distribution of the studies is shown in Figure 3. Starting with 2017, there was a trend upwards regarding the number of works published per year, with an overall peak in $2020(n=11)$. The 2021 number was low as the last database search was done in December of 2020, thus only including some publications that date from 2021. Possible reasons for the distribution, albeit based on relatively small numbers, might be found in the publication dates of IPCC reports in 2014 and 2018 [15,68]. These reports could have caused and/or influenced the rising numbers after 2014 and the trend starting in 2017.

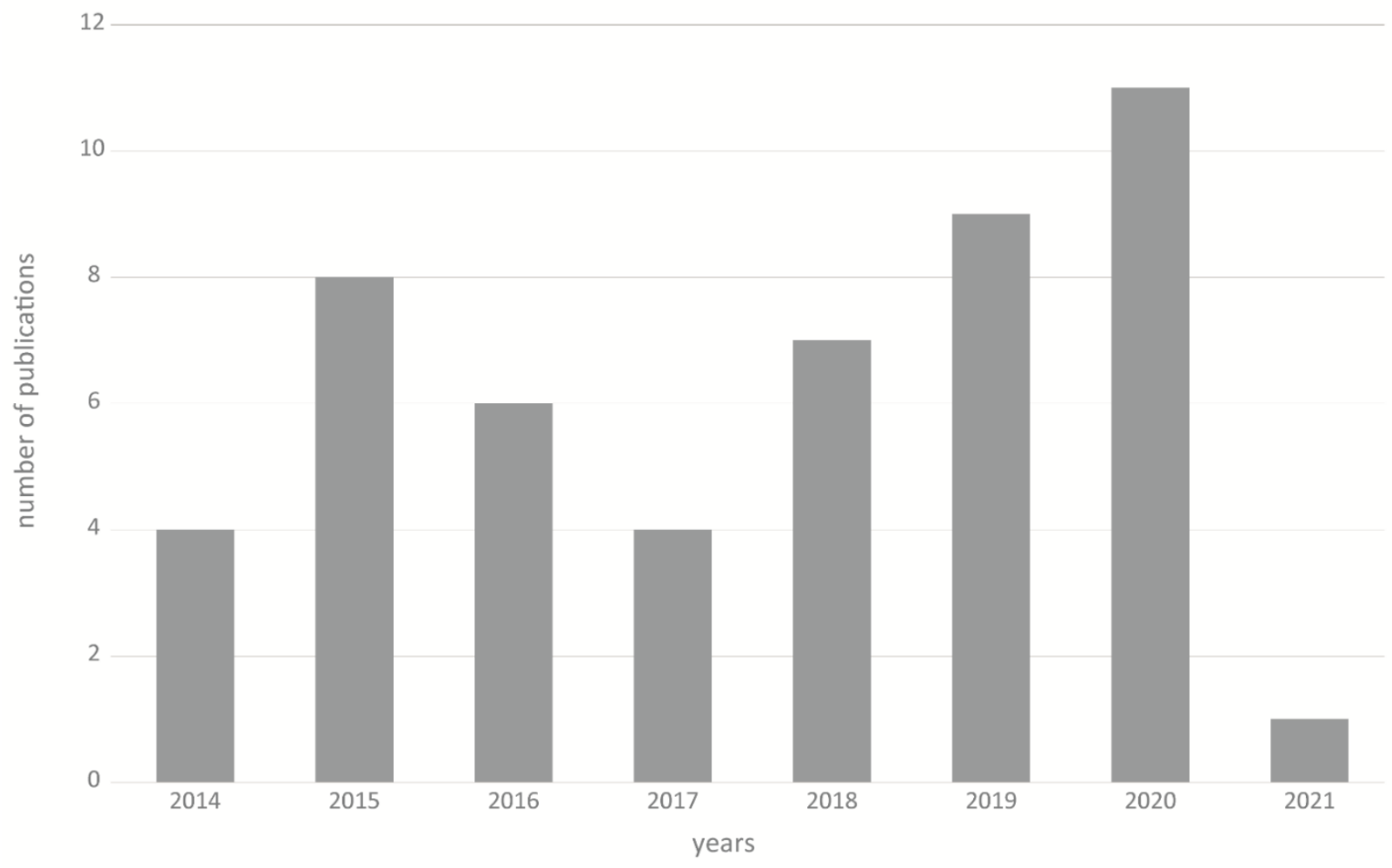

Figure 3. Reviewed publications per year. For 2021, the number is incomplete as only some publications assigned to journal issues of that year were found at the end of 2020.

A generally upward tendency was highlighted in existing climate change-related reviews. For the time between 1980 and 2014, Haunschild et al. [69] observed a strongly pronounced overall growth regarding climate change research and also a growth in involved disciplines and subfields, such as adaptation, vulnerability, and impacts. Regarding climate change vulnerability assessment studies, a strong rise in publications between 2006 and 2016 [16], respectively, 2000 and 2011 was observed [17]. Zhang et al. detected a rise in vulnerability assessments in the context of climate change after IPCC 2001, especially 
between 2005 and 2017 [27]. Siders described a rapid growth in adaptive capacity research starting around 2001 with IPCC TAR [9]. An ascending trend, especially between 2007 and 2016, was also found in research concerning adaptation in the coastal zone respectively on small islands, possibly triggered by the IPCC AR 5 's call for adaptation planning future scenario development and in-depth vulnerability assessment [25]. Haunschild et al. [69] also linked the "exponential growth of climate change literature" (p. 7) disclosed by their analysis to be supposedly induced by IPCC Assessment Reports and their increasing influence on the attractiveness of climate change research. Additionally, they emphasized that climate change effects, impacts, and risks are becoming increasingly tangible.

Regarding our initial set of publications, there was a small bump in the publication totals in 2017 and 2019 (Scopus), respectively a slight bump/stagnation in 2017 and otherwise rising numbers (WoS). Thus, the distribution featured by the 50 publications analyzed in depth was not only found in this subset but rather in the entirety of researched literature. When applying the search terms climat * chang * adapt * and searching in title, abstract, and keywords, there was a rise, which in the Scopus case was smaller in 2017 and 2019, while constant for WoS. For climat * chang * vulnerab *, both databases featured constant rises.

Considering the actuality and significance of climate change-related topics in politics, spatial, and urban planning, as well as in many other areas, it cannot be expected that the number of publications in fields related to climate change adaptation will decrease any time soon.

RQ 2: What are the geographical scopes of respective studies, and where are the authors located?

As far as the study areas were concerned, Figure 4a depicts the distribution of studies per continent. A maximum of 18 were located in Asia (11 alone in China). Europe $(n=8)$, Africa $(n=7)$, and North America $(n=5)$ were the runners-up. Four publications regarded localities on multiple continents (e.g., [70]—cities in developing countries), and three featured no explicit study area. On the other hand, Figure $4 \mathrm{~b}$ shows in which continent the authors' affiliations were located. Hereby, only one occurrence per continent and publication was counted. So, when a paper was written by two authors in China and three in Europe, that counted as one for each of these continents. This was done to avoid overweighting by publications with many authors. Results showed that Europe and Asia topped the list with 22, respectively 18 authorships. China alone accounted for twelve. Following up were North America $(n=12)$ and Africa $(n=8)$.

A clear dominance of Asia and especially China was found when it came to the location in which the research was conducted. In addition, Africa was well represented. This is in line with the fact that the world's fastest-growing cities are located in Asia and Africa, and the share of the urban population there is constantly rising. When it comes to bigger conurbations, between 2018 and 2030, the number of cities with 500,000 inhabitants or more is expected to grow by $57 \%$ (Africa) and by $23 \%$ (Asia), respectively. The number of cities with over five or ten million dwellers is rising fastest in these areas as well [2]. In addition, cities in these regions are among the most affected by climate change influences $[3,70,72,73]$. However, when it comes to the places the respective authors were active, Europe and North America were overrepresented compared to the case study locations. Africa and Asia were similarly represented as study and author locations. This suggests that a lot of work is done in the region of the regarded case studies. Yet, especially in Europe and North America, researchers frequently worked on out-of-continent study areas. This dominance of western countries (Global North) regarding publication activity in climate change research is discernible in bibliometric analyses as well $[69,74]$. Sietsma et al. [74] also found "significant topic biases by geographic location" (p. 1). Their study revealed that, according to interviewed experts and the "Big Literature" they reviewed, inequalities between Global North and South are an enduring issue in climate change adaptation research. Applying a database search on Scopus with the search term climat * chang * africa (in title, abstract, keywords) from 2014-today yielded about 6140 records for the ten most active country affiliations of the research (database query done in May 2021). The top 
three nations were the US with about 1900, South Africa with about 1880, and the UK with about 1320 publications. Kenya, with approximately 420 records, is the only other African country in the top ten. When repeating the query with a focus on research done on Asia (climat * chang * asia-title, abstract, keywords), there were about 6370 records distributed among the top ten active countries. Here, China with about 2740, the US with about 1900, and the UK with approximately 900 publications make the top three. With Japan on rank 6 and about 600, India on rank 7 with about 580, and South Korea on rank 8 with approximately 380 publications, there are three more Asian countries in the top ten. However, especially when leaving aside China, non-Asian countries were responsible for a large share of research on Asia.

a)

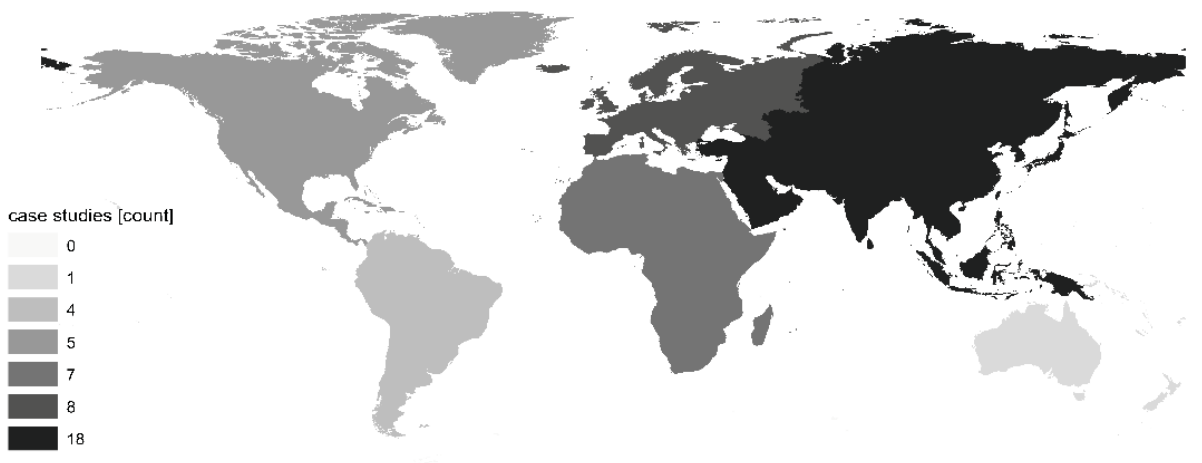

b)

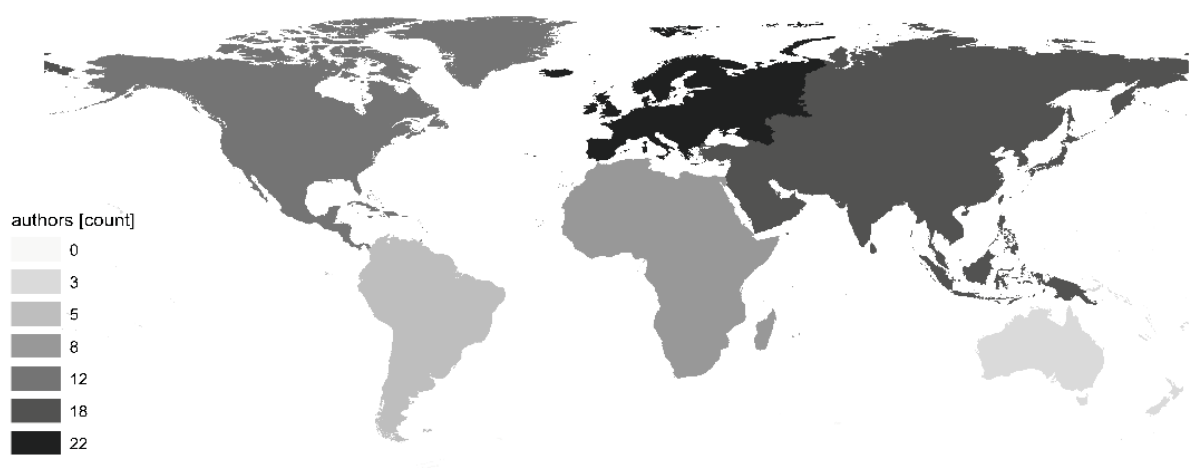

Figure 4. Geographical distribution of research focus. Locations of case studies (a) and authors (b). Map data from Esri [71].

RQ 3: What study types dominate-case studies or conceptual/theoretical works, quantitative or qualitative analyses, and what target audiences are focused on by the reviewed studies?

Usually, the reviewed studies encompassed a theoretical framework and a case study. Only a few were merely theoretical and focused on the creation of a conceptual framework $(n=9)$. Most studies applied a quantitative $(n=17)$ or mixed methods approach $(n=25$, e.g., [70]). Additionally, mostly indicator-based research was done, or the creation of an index was an integral part of the publications. When it came to the target groups, almost entirely decision-makers, politicians, stakeholders, or planners were addressed $(n=49)$. Only in ten studies was the scientific community targeted explicitly as well. For one publication, it was unclear who was mainly addressed.

The fact that the analyzed set of publications featured mainly case studies often developed indices and addressed almost uniformly practitioners of different kinds supports the notion that climate change adaptation and its evidence base are discerned as rather practical topics. Regarding that, Greiving et al. [13] strongly encouraged closing the 
science-policy gap by involving stakeholders ("collaborative science") as doing so yields better outcomes. Enhancing the practical utility of risk assessments for policymakers and practitioners is also occasionally the stated goal in climate change adaptation research [10]. The IPCC also encourages a multifaceted stakeholder engagement at the urban scale [3].

The dominance of quantitative and mixed methods approaches is not only found in our compilation. Singh et al. found that about two-thirds of their reviewed studies were either applying quantitative (and index-based) or mixed methodologies [22]. Especially for vulnerability assessments, there is a large quantity of research dedicated to index creation in various sectors [75-77].

RQ 4: What climate change-related conceptual frameworks are referred to, and how are they defined?

Figure 5 shows the main concepts dealt with in the studies. Summing up the occurrences, the resulting number was larger than 50 . This is because some studies focus on more than one concept (e.g., [78]). The total number of concepts was 64 . Vulnerability was the most popular $(n=31)$, making up for almost half of the total main concepts. Further concepts focused on frequently were resilience $(n=8)$, risk $(n=6)$, impact $(n=6)$, and adaptive capacity $(n=5)$.

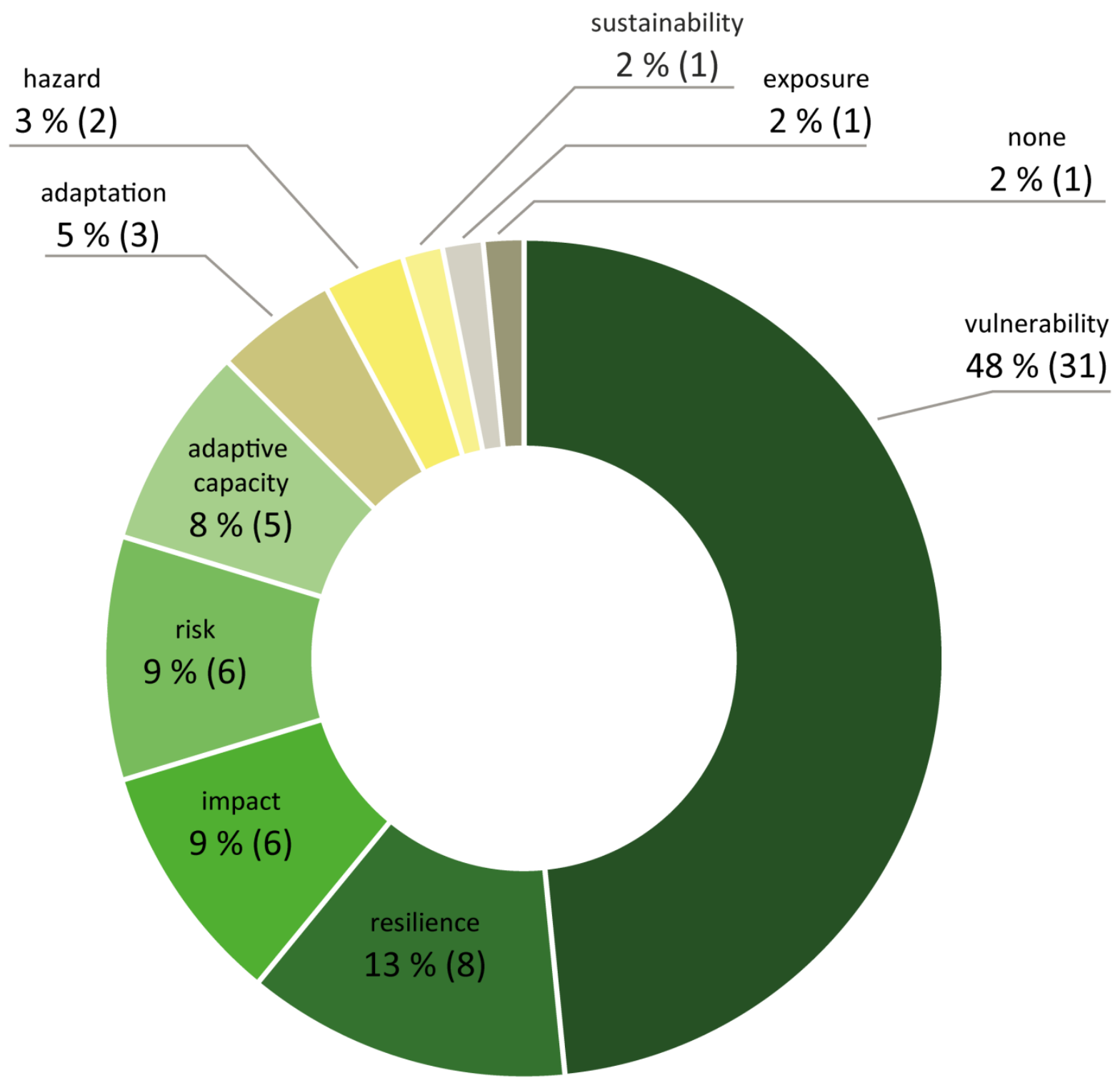

Figure 5. Concepts dealt with in the reviewed publications. 
Regarding the definitions given in order to specify the main concepts, there was no uniformity. Many concepts were defined in various IPCC Assessment Reports, but we saw a varying understanding of vulnerability, risk, etc., nonetheless. Figure 6 shows a categorization with the classes old IPCC (2007), new IPCC (2014), old IPCC informed, new IPCC informed, own, none, and literature derived. Very often, no explicit definition was given $(n=12)$. Direct $(n=11)$ and indirect $(n=17)$ IPCC definitions were in the majority. Over half of the publications $(56 \%, n=28)$ referred somehow to IPCC contents.

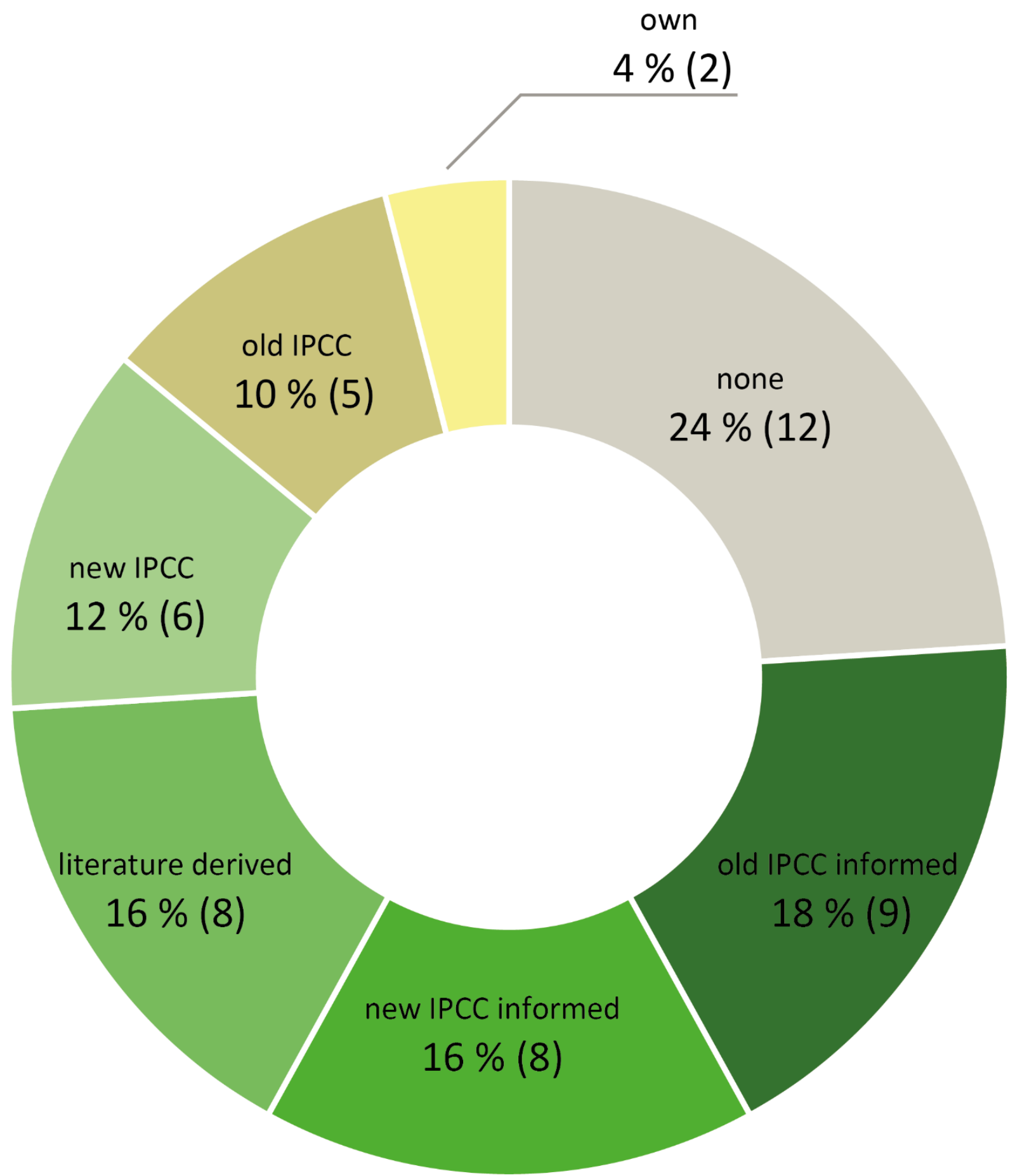

Figure 6. Definitions applied for the main concept of the research. 
When it comes to the main concepts dealt with in the studies, there was a strong focus on vulnerability while, in total, there was a multitude of different concepts. The dominance of vulnerability can be based on the prominent featuring by the IPCC reports (on which many studies rely when defining concepts). Studies analyzing massive research data related to climate change adaptation also confirmed the outstanding significance of vulnerability as a keyword/topic [74,79]. The plurality and diversity of understandings, however, were still large (see [80]). That made it difficult or even impossible to compare studies that, for example, claimed to deal with vulnerability, but behind this tag, there can be many understandings of what vulnerability is. For vulnerability assessments in India, Singh et al. found that $26 \%$ of the reviewed studies related to IPCC definitions, while $25 \%$ did not clearly define vulnerability at all [22]. In the findings of her review on adaptive capacity, Siders stated that the field is interdisciplinary, very fragmented, dealing with multiple scales, topical sectors, locations, multiple methods/metrics that are sometimes contradictory [9]. Regarding the notion of exposure, there are also conceptual mismatches [10].

\section{Conclusions}

Our scoping review explored the status quo on conceptual frameworks applied for the assessment of climate change effects in urban areas. We systematically reviewed a number of interdisciplinary publications with a particular emphasis on the usage of terms and concepts. The reviewed field of research was found to be a globally active area with a research focus on under-developed and deprived regions in the Global South (e.g., Africa and Asia), while researchers themselves were often located in Europe and North America. The disclosed dynamics in the field contribute to an ongoing ambiguity concerning the multitude of conceptual frameworks and blurred and sometimes contradictorily used definitions. The dominant climate change-related concept dealt with in the reviewed studies was vulnerability. However, related concepts, such as resilience, risk, or impact, were also frequently considered. Definitions for those concepts were found to be informed by various sources, with the IPCC influencing more than half of them.

A possible explanation for the observed temporal trends could be seen in a dependence on IPCC publications. This potential reflection of publication patterns in response to the publication of IPCC reports was also found in existing reviews and studies and their revealed trends (immediate response and triggered, lagged publications). The foci on IPCC reports found in the papers analyzed support this supposed correlation.

The observed discrepancy in the geographical distributions and scopes of researchers versus those being researched can be linked to postcolonial tendencies in research in general. For Africa and research on Africa, Mawere and van Stam showed that scientists "often from countries with unresolved colonial baggage, cast their normalizing shadows over African realities" (p. 168). The dominance of foreign research was often particularly high. As of 2018, for example, almost $60 \%$ of HIV research on Africa was found to be done by foreigners - a tendency also found in various other disciplines [81].

In the reviewed set of literature, case studies were found to be dominant with little purely conceptual works. This dominance of applied case studies, employing a variety of concepts and associated definitions, implicates that mainstreaming of conceptual frameworks, definitions, and methodologies is not very advanced and not tackled extensively. Furthermore, the preeminence of vulnerability and the ways in which this concept has been used in the literature (vulnerability assessments, e.g.) support the conclusion that the research looked at was mostly driven by applied viewpoints. Vulnerability is also featured strongly in the IPCC reports, which, again, supports the already outlined publication pattern in response to the IPCC publications.

\section{Outlook}

Successfully implementing evidence-based climate change adaptation in urban areas requires a consistent scientific discourse regarding concepts, definitions, approaches, 
frameworks, and methods. Standardized approaches are especially helpful when a representative selection of cities is observed, facilitating the transfer of insights for other cities in similar regions or with similar characteristics. On that basis, a broad spectrum of more sophisticated studies with increased explanatory power can be initiated [31]. This is also imperative as more studies and research are expected in various world regions and as research addressing policy and practice can only be valuable when it is based on a strong, consistent foundation. Our results contribute to the necessary consensus building ahead through highlighting existing incongruences both at terminological and conceptual levels. The scoping review conducted will thus hopefully support facilitating research and transfer of evidence into policymaking in this timely field of societal relevance. Our obtained results are also intended to inform research and practice likewise. The thorough overview and understanding of conceptual climate change-related frameworks presented in our work will hopefully support evidence-led research and policymaking guided by solid conceptual understandings, including changes and variations of the latter.

Apart from the described unification processes, further research, also preparatory for actual assessments, might focus on characterizing cities in order to understand where their vulnerabilities or resilience originate. Here, a look at regional/cultural genetic city types might be helpful. By doing so, specific characteristics in structure or morphology influencing climate change impacts and effects could be carved out in order to understand them better. When comparing various city types, it is possible to gain an understanding of which structures and morphologies endanger a specific urban area regarding climate change issues and which do not. This can be an important asset for the future of urban planning, including traffic planning, as well as urban design and architecture.

Author Contributions: Conceptualization, F.K. and R.W.; methodology, F.K. and R.W.; software, F.K.; validation, F.K.; formal analysis, F.K.; investigation, F.K.; resources, F.K.; data curation, F.K.; writingoriginal draft preparation, F.K.; writing-review and editing, F.K., R.W. and D.G.; visualization, F.K.; supervision, R.W. and D.G.; project administration, F.K.; funding acquisition, F.K. and D.G. All authors have read and agreed to the published version of the manuscript.

Funding: We acknowledge financial support by the Deutsche Forschungsgemeinschaft and Technische Universität Dortmund/TU Dortmund University within the funding program Open Access Publishing.

Conflicts of Interest: The authors declare no conflict of interest.

\section{References}

1. The World Bank. World Bank Open Data: Urban Development. Available online: https://data.worldbank.org/topic/urbandevelopment (accessed on 1 March 2021).

2. UN DESA. World Urbanization Prospects: The 2018 Revision; United Nations: New York, NY, USA, 2019; ISBN 978-92-1-148319-2.

3. Revi, A.; Satterthwaite, D.E.; Aragón-Durand, F.; Corfee-Morlot, J.; Kiunsi, R.B.R.; Pelling, M.; Roberts, D.C.; Solecki, W. Urban Areas. In Climate Change 2014: Impacts, Adaptation and Vulnerability. Part A: Global and Sectoral Aspects: Contribution of Working Group II to the IPCC Fifth Assessment Report of the Intergovernmental Panel on Climate Change; IPCC, Ed.; Cambridge University Press: Cambridge, UK, 2014; pp. 535-612, ISBN 978-1-107-05807-1.

4. $\quad$ Bai, X.; Dawson, R.; Ürge-Vorsatz, D.; Delgado, G.C.; Barau, A.S.; Dhakal, S.; Dodman, D.; Leonardsen, L.; Masson-Delmotte, V.; Roberts, D.C.; et al. Six research priorities for cities and climate change. Nature 2018, 555, 23-25. [CrossRef]

5. Oppenheimer, M.; Campos, M.; Warren, R.; Birkmann, J.; Luber, G.; O’Neill, B.; Takahashi, K. Emergent Risks and Key Vulnerabilities. In Climate Change 2014: Impacts, Adaptation and Vulnerability. Part A: Global and Sectoral Aspects: Contribution of Working Group II to the IPCC Fifth Assessment Report of the Intergovernmental Panel on Climate Change; IPCC, Ed.; Cambridge University Press: Cambridge, UK, 2014; pp. 1039-1099, ISBN 978-1-107-05807-1.

6. Birkmann, J.; Greiving, S.; Serdeczny, O.M. Das Assessment von Vulnerabilitäten, Risiken und Unsicherheiten. In Klimazandel in Deutschland; Brasseur, G.P., Jacob, D., Schuck-Zöller, S., Eds.; Springer: Berlin/Heidelberg, Germany, 2017; pp. 267-276, ISBN 978-3-662-50396-6.

7. Füssel, H.-M.; Klein, R.J. Climate Change Vulnerability Assessments: An Evolution of Conceptual Thinking. Clim. Chang. 2006, 75, 301-329. [CrossRef]

8. Biesbroek, R.; Berrang-Ford, L.; Ford, J.D.; Tanabe, A.; Austin, S.E.; Lesnikowski, A. Data, concepts and methods for large-n comparative climate change adaptation policy research: A systematic literature review. Wiley Interdiscip. Rev. Clim. Chang. 2018, 9, 9. [CrossRef] 
9. Siders, A. Adaptive capacity to climate change: A synthesis of concepts, methods, and findings in a fragmented field. Wiley Interdiscip. Rev. Clim. Chang. 2019, 10, e573. [CrossRef]

10. Connelly, A.; Carter, J.; Handley, J.; Hincks, S. Enhancing the Practical Utility of Risk Assessments in Climate Change Adaptation. Sustainability 2018, 10, 1399. [CrossRef]

11. IPCC. Impacts, Adaptation and Vulnerability; Cambridge University Press: Cambridge, UK, 2007; ISBN 9780521880107.

12. IPCC. Impacts, Adaptation, and Vulnerability; Cambridge University Press: Cambridge, UK, 2001; ISBN 0521807689.

13. Greiving, S.; Zebisch, M.; Schneiderbauer, S.; Fleischhauer, M.; Lindner, C.; Lückenkötter, J.; Buth, M.; Kahlenborn, W.; Schauser, I. A consensus based vulnerability assessment to climate change in Germany. Int. J. Clim. Chang. Strat. Manag. 2015, 7, $306-326$. [CrossRef]

14. Field, C.B. (Ed.) Managing the Risks of Extreme Events and Disasters to Advance Climate Change Adaptation: Special Report of the Intergovernmental Panel on Climate Change; Cambridge University Press: Cambridge, UK, 2012; ISBN 978-1-107-02506-6.

15. Field, C.B.; Barros, V.R.; Mastrandrea, M.D.; Mach, K.J.; Abdrabo, M.-K.; Adger, N.; Anokhin, Y.A.; Anisimov, O.A.; Arent, D.J.; Barnett, J. Summary for policymakers. In Climate Change 2014: Impacts, Adaptation and Vulnerability. Part A: Global and Sectoral Aspects: Contribution of Working Group II to the IPCC Fifth Assessment Report of the Intergovernmental Panel on Climate Change; IPCC, Ed.; Cambridge University Press: Cambridge, UK, 2014; pp. 1-32, ISBN 978-1-107-05807-1.

16. Di Matteo, G.; Nardi, P.; Grego, S.; Guidi, C. Bibliometric analysis of Climate Change Vulnerability Assessment research. Environ. Syst. Decis. 2018, 38, 508-516. [CrossRef]

17. Tonmoy, F.N.; El-Zein, A.; Hinkel, J. Assessment of vulnerability to climate change using indicators: A meta-analysis of the literature. Wiley Interdiscip. Rev. Clim. Chang. 2014, 5, 775-792. [CrossRef]

18. Berrang-Ford, L.; Pearce, T.; Ford, J.D. Systematic review approaches for climate change adaptation research. Reg. Environ. Chang. 2015, 15, 755-769. [CrossRef]

19. Ribeiro, P.J.G.; Gonçalves, L.A.P.J. Urban resilience: A conceptual framework. Sustain. Cities Soc. 2019, 50, 101625. [CrossRef]

20. Lankao, P.R.; Qin, H. Conceptualizing urban vulnerability to global climate and environmental change. Curr. Opin. Environ. Sustain. 2011, 3, 142-149. [CrossRef]

21. EURAC Research. Guidance for Using the IPCC AR5 Risk Concept in Vulnerability Assessments. Available online: http: //www.eurac.edu/en/research/projects/pages/projectdetail4261.aspx (accessed on 1 March 2021).

22. Singh, C.; Deshpande, T.; Basu, R. How do we assess vulnerability to climate change in India? A systematic review of literature. Reg. Environ. Chang. 2017, 17, 527-538. [CrossRef]

23. Olmstead, S. Climate change adaptation and water resource management: A review of the literature. Energy Econ. 2014, 46, 500-509. [CrossRef]

24. Fatorić, S.; Seekamp, E. Are cultural heritage and resources threatened by climate change? A systematic literature review. Clim. Chang. 2017, 142, 227-254. [CrossRef]

25. Hafezi, M.; Sahin, O.; Stewart, R.; Mackey, B. Creating a Novel Multi-Layered Integrative Climate Change Adaptation Planning Approach Using a Systematic Literature Review. Sustainability 2018, 10, 4100. [CrossRef]

26. Debortoli, N.S.; Sayles, J.S.; Clark, D.G.; Ford, J.D. A systems network approach for climate change vulnerability assessment. Environ. Res. Lett. 2018, 13, 104019. [CrossRef]

27. Zhang, Q.; Xue, H.; Tang, H. Knowledge Domain and Emerging Trends in Vulnerability Assessment in the Context of Climate Change: A Bibliometric Analysis (1991-2017). Knowl. Organ. 2018, 45, 467-483. [CrossRef]

28. Chapman, S.; Watson, J.; Salazar, A.; Thatcher, M.; McAlpine, C. The impact of urbanization and climate change on urban temperatures: A systematic review. Landsc. Ecol. 2017, 32, 1921-1935. [CrossRef]

29. Miller, J.D.; Hutchins, M. The impacts of urbanisation and climate change on urban flooding and urban water quality: A review of the evidence concerning the United Kingdom. J. Hydrol. Reg. Stud. 2017, 12, 345-362. [CrossRef]

30. Yazdanfar, Z.; Sharma, A. Urban drainage system planning and design-Challenges with climate change and urbanization: A review. Water Sci. Technol. 2015, 72, 165-179. [CrossRef] [PubMed]

31. Hunt, A.; Watkiss, P. Climate change impacts and adaptation in cities: A review of the literature. Clim. Chang. 2010, 104, 13-49. [CrossRef]

32. Dhar, T.K.; Khirfan, L. Climate change adaptation in the urban planning and design research: Missing links and research agenda. J. Environ. Plan. Manag. 2016, 60, 602-627. [CrossRef]

33. Kitchenham, B. Procedures for Performing Systematic Reviews. Keele University Technical Report TR/SE-0401. 2004. Available online: https:/ / www.inf.ufsc.br/ \{\}aldo.vw/kitchenham.pdf (accessed on 4 August 2021).

34. Pickering, C.; Byrne, J. The benefits of publishing systematic quantitative literature reviews for PhD candidates and other early-career researchers. High. Educ. Res. Dev. 2014, 33, 534-548. [CrossRef]

35. Borrego, M.; Foster, M.J.; Froyd, J.E. Systematic Literature Reviews in Engineering Education and Other Developing Interdisciplinary Fields. J. Eng. Educ. 2014, 103, 45-76. [CrossRef]

36. Moher, D.; Liberati, A.; Tetzlaff, J.; Altman, D.G.; The PRISMA Group. Preferred Reporting Items for Systematic Reviews and Meta-Analyses: The PRISMA Statement. PLoS Med. 2009, 6, e1000097. [CrossRef] [PubMed]

37. Haddaway, N.R.; Macura, B.; Whaley, P.; Pullin, A. ROSES RepOrting standards for Systematic Evidence Syntheses: Pro forma, flow-diagram and descriptive summary of the plan and conduct of environmental systematic reviews and systematic maps. Environ. Évid. 2018, 7, 7. [CrossRef] 
38. Harzing, A.-W.; Alakangas, S. Google Scholar, Scopus and the Web of Science: A longitudinal and cross-disciplinary comparison. Science 2016, 106, 787-804. [CrossRef]

39. Shaffril, H.A.M.; Samsuddin, S.F.; Abu Samah, A. The ABC of systematic literature review: The basic methodological guidance for beginners. Qual. Quant. 2021, 55, 1319-1346. [CrossRef]

40. Feyissa, G.; Zeleke, G.; Gebremariam, E.; Bewket, W. GIS based quantification and mapping of climate change vulnerability hotspots in Addis Ababa. Geoenviron. Disasters 2018, 5, 14. [CrossRef]

41. Tapia, C.; Abajo, B.; Feliu, E.; Mendizabal, M.; Martinez, J.A.; Fernández, J.G.; Laburu, T.; Lejarazu, A. Profiling urban vulnerabilities to climate change: An indicator-based vulnerability assessment for European cities. Ecol. Indic. 2017, 78, 142-155. [CrossRef]

42. Huynh, H.L.T.; Do, A.T.; Dao, T.M. Climate change vulnerability assessment for Can Tho city by a set of indicators. Int. J. Clim. Chang. Strat. Manag. 2020, 12, 147-158. [CrossRef]

43. Lyle, T.; Mills, T. Assessing coastal flood risk in a changing climate for the City of Vancouver. Can. Water Resour. J. Rev. Can. Ressour. Hydr. 2016, 41, 343-352. [CrossRef]

44. Moore, T.L.; Gulliver, J.S.; Stack, L.; Simpson, M.H. Stormwater management and climate change: Vulnerability and capacity for adaptation in urban and suburban contexts. Clim. Chang. 2016, 138, 491-504. [CrossRef]

45. Bai, H.; Dong, X.; Zeng, S.; Chen, J. Assessing the potential impact of future precipitation trends on urban drainage systems under multiple climate change scenarios. Int. J. Glob. Warm. 2016, 10, 437. [CrossRef]

46. Feilberg, M.; Mark, O. Integrated Urban Water Management: Improve Efficient Water Management and Climate Change Resilience in Cities. In Sustainable Water Management in Urban Environments; The Handbook of Environmental Chemistry; Springer: Cham, Switzerland, 2016; Volume 47, pp. 1-32. [CrossRef]

47. Sánchez, F.G.; Solecki, W.D.; Batalla, C.R. Climate change adaptation in Europe and the United States: A comparative approach to urban green spaces in Bilbao and New York City. Land Use Policy 2018, 79, 164-173. [CrossRef]

48. Rome, E.; Bogen, M.; Lückerath, D.; Ullrich, O.; Worst, R.; Streberová, E.; Dumonteil, M.; Mendizabal, M.; Abajo, B.; Feliu, E.; et al. Risk-Based Analysis of the Vulnerability of Urban Infrastructure to the Consequences of Climate Change. Adv. Sci. Technol. Secur. Appl. 2019, 55-75. [CrossRef]

49. Suonan, J.; Classen, A.; Sanders, N.J.; He, J. Plant phenological sensitivity to climate change on the Tibetan Plateau and relative to other areas of the world. Ecosphere 2019, 10, e02543. [CrossRef]

50. Doroftei, M.; Anastasiu, P. Potential Impacts of Climate Change on Habitats and Their Effects on Invasive Plant Species in Danube Delta Biosphere Reserve, Romania. Adv. Glob. Chang. Res. 2014, 58, 267-278. [CrossRef]

51. Kantamaneni, K.; Rice, L.; Yenneti, K.; Campos, L. Assessing the Vulnerability of Agriculture Systems to Climate Change in Coastal Areas: A Novel Index. Sustainability 2020, 12, 4771. [CrossRef]

52. Pinnegar, J.K.; Engelhard, G.H.; Norris, N.J.; Theophille, D.; Sebastien, R.D. Assessing vulnerability and adaptive capacity of the fisheries sector in Dominica: Long-term climate change and catastrophic hurricanes. ICES J. Mar. Sci. 2019, 76, $1353-1367$. [CrossRef]

53. Kuefner, W.; Hofmann, A.M.; Geist, J.; Raeder, U. Evaluating climate change impacts on mountain lakes by applying the new silicification value to paleolimnological samples. Sci. Total Environ. 2020, 715, 136913. [CrossRef]

54. Afriyie-Kraft, L.; Zabel, A.; Damnyag, L. Adaptation strategies of Ghanaian cocoa farmers under a changing climate. For. Policy Econ. 2020, 113, 102115. [CrossRef]

55. Misana, S.B.; Tilumanywa, V.T. An Assessment of the Vulnerability and Response of Coastal Communities to Climate Change Impact in Lindi Region, Southern Tanzania; Springer Science and Business Media LLC: Cham, Switzerland, 2019; pp. 117-153.

56. Lesnikowski, A.; Ford, J.D.; Biesbroek, R.; Berrang-Ford, L. A policy mixes approach to conceptualizing and measuring climate change adaptation policy. Clim. Chang. 2019, 156, 447-469. [CrossRef]

57. Ruiu, M.L.; Ragnedda, M.; Ruiu, G. Similarities and differences in managing the Covid-19 crisis and climate change risk. J. Knowl. Manag. 2020, 24, 2597-2614. [CrossRef]

58. Scott-Parker, B.; Kumar, R. Fijian adolescents' understanding and evaluation of climate change: Implications for enabling effective future adaptation. Asia Pac. Viewp. 2018, 59, 47-59. [CrossRef]

59. Agathangelidis, I.; Cartalis, C.; Santamouris, M. Integrating Urban Form, Function, and Energy Fluxes in a Heat Exposure Indicator in View of Intra-Urban Heat Island Assessment and Climate Change Adaptation. Climate 2019, 7, 75. [CrossRef]

60. Straka, M.; Sodoudi, S. Evaluating climate change adaptation strategies and scenarios of enhanced vertical and horizontal compactness at urban scale (a case study for Berlin). Landsc. Urban Plan. 2018, 183, 68-78. [CrossRef]

61. Azevedo, I.; Leal, V. Methodologies for the evaluation of local climate change mitigation actions: A review. Renew. Sustain. Energy Rev. 2017, 79, 681-690. [CrossRef]

62. Philp, G.; Cohen, A. Municipal climate change adaptation and mitigation: From planning to action in Nova Scotia. J. Environ. Plan. Manag. 2019, 63, 1927-1945. [CrossRef]

63. Hu, Q.; Tang, Z.; Zhang, L.; Xu, Y.; Wu, X.; Zhang, L. Evaluating climate change adaptation efforts on the US 50 states' hazard mitigation plans. Nat. Hazards 2018, 92, 783-804. [CrossRef]

64. Abutaleb, K.A.A.; Mohammed, A.H.E.-S.; Ahmed, M.H.M. Climate Change Impacts, Vulnerabilities and Adaption Measures for Egypt's Nile Delta. Earth Syst. Environ. 2018, 2, 183-192. [CrossRef] 
65. McCormick, S. Assessing climate change vulnerability in urban America: Stakeholder-driven approaches. Clim. Chang. 2016, 138, 397-410. [CrossRef]

66. Amuzu, J.; Jallow, B.P.; Kabo-Bah, A.T.; Yaffa, S. The Climate Change Vulnerability and Risk Management Matrix for the Coastal Zone of The Gambia. Hydrology 2018, 5, 14. [CrossRef]

67. Mohan, D.; Sinha, S. Assessing vulnerability to climate change in the Ganges Basin using a combined macro- and micro-level approach. Clim. Dev. 2016, 8, 312-323. [CrossRef]

68. IPCC. Global Warming of $1.5^{\circ} \mathrm{C}$ : An IPCC Special Report on the Impacts of Global Warming of $1.5^{\circ} \mathrm{C}$ Above Pre-Industrial Levels and Related Global Greenhouse Gas Emission Pathways, in the Context of Strengthening the Global Response to the Threat of Climate Change, Sustainable Development, and Efforts to Eradicate Poverty. Available online: https://www.ipcc.ch/sr15/ (accessed on 4 August 2021).

69. Haunschild, R.; Bornmann, L.; Marx, W. Climate Change Research in View of Bibliometrics. PLoS ONE 2016, 11, e0160393. [CrossRef] [PubMed]

70. Filho, W.L.; Balogun, A.-L.; Olayide, O.E.; Azeiteiro, U.M.; Ayal, D.Y.; Muñoz, P.D.C.; Nagy, G.J.; Bynoe, P.; Oguge, O.; Toamukum, N.Y.; et al. Assessing the impacts of climate change in cities and their adaptive capacity: Towards transformative approaches to climate change adaptation and poverty reduction in urban areas in a set of developing countries. Sci. Total Environ. 2019, 692, 1175-1190. [CrossRef]

71. Esri. World Continents (Shapefile). 2020. Available online: https:/ /hub.arcgis.com/datasets/esri::world-continents/explore? location=-69.775770\%2C-50.288541\%2C0.94 (accessed on 4 January 2021).

72. Adenle, A.A.; Ford, J.D.; Morton, J.; Twomlow, S.; Alverson, K.; Cattaneo, A.; Cervigni, R.; Kurukulasuriya, P.; Huq, S.; Helfgott, A.; et al. Managing Climate Change Risks in Africa-A Global Perspective. Ecol. Econ. 2017, 141, 190-201. [CrossRef]

73. Busby, J.; Smith, T.G.; Krishnan, N.; Wight, C.; Vallejo-Gutierrez, S. In harm's way: Climate security vulnerability in Asia. World Dev. 2018, 112, 88-118. [CrossRef]

74. Sietsma, A.J.; Ford, J.D.; Callaghan, M.W.; Minx, J.C. Progress in climate change adaptation research. Environ. Res. Lett. 2021, 16, 054038. [CrossRef]

75. Malakar, K.; Mishra, T. Assessing socio-economic vulnerability to climate change: A city-level index-based approach. Clim. Dev. 2016, 9, 348-363. [CrossRef]

76. Zanetti, V.B.; Junior, W.C.D.S.; De Freitas, D.M. A Climate Change Vulnerability Index and Case Study in a Brazilian Coastal City. Sustainability 2016, 8, 811. [CrossRef]

77. Edmonds, H.; Lovell, J.; Lovell, C. A new composite climate change vulnerability index. Ecol. Indic. 2020, 117, 106529. [CrossRef]

78. Hobbie, S.E.; Grimm, N.B. Nature-based approaches to managing climate change impacts in cities. Philos. Trans. R. Soc. B Biol. Sci. 2020, 375, 20190124. [CrossRef] [PubMed]

79. Wang, Z.; Zhao, Y.; Wang, B. A bibliometric analysis of climate change adaptation based on massive research literature data. J. Clean. Prod. 2018, 199, 1072-1082. [CrossRef]

80. Fleischhauer, M.; Greiving, S.; Lindner, C.; Lückenkötter, J.; Schauser, I. Analyse der Literatur zu Klimawirkungen in Deutschland: Ein Gesamtbild mit Lücken. In Klimawandel in Deutschland; Brasseur, G.P., Jacob, D., Schuck-Zöller, S., Eds.; Springer: Berlin/Heidelberg, Germany, 2017; pp. 277-286, ISBN 978-3-662-50396-6.

81. Mawere, M.; van Stam, G. Research in Africa for Africa? Probing the Effect and Credibility of Research Done by Foreigners for Africa. In Information and Communication Technologies for Development. Strengthening Southern-Driven Cooperation as a Catalyst for ICT4D; Nielsen, P., Kimaro, H.C., Eds.; Springer International Publishing: Cham, Switzerland, 2019; pp. 168-179, ISBN 978-3-030-19114-6. 